\title{
Clinical trial of local anesthetic protocols for acute pain associated with caustic paste disbudding in dairy calves
}

\author{
Charlotte B. Winder, ${ }^{*}$ Stephen J. LeBlanc, ${ }^{*}$ Derek B. Haley, ${ }^{*}$ Kerry D. Lissemore, ${ }^{*}$ M. Ann Godkin, $\dagger$ \\ and Todd F. Duffield*1 \\ *Department of Population Medicine, University of Guelph, Ontario, N1G 2W1 Canada \\ †Ontario Ministry of Agriculture, Food, and Rural Affairs, Elora, Ontario, NOB 1S0 Canada
}

\begin{abstract}
Caustic paste disbudding is becoming more commonplace in North America. A large body of work has examined pain control for cautery disbudding and surgical dehorning, but fewer studies have evaluated pain control for caustic paste disbudding, and results conflict regarding benefits of local anesthesia. In humans, the pain associated with a caustic, chemical burn can differ in nature, duration, and intensity compared with a thermal burn. The objective of this clinical trial was to evaluate the effects of either a lidocaine cornual nerve block or a topical anesthetic incorporated into caustic paste on the acute pain of caustic paste disbudding. Seventy-two Holstein-Friesian calves housed in groups with an automated milk feeder were enrolled into 18 replicates balanced on age and assigned to 1 of 4 treatments: sham (S), placebo paste and a saline cornual block; topical (T), a novel caustic paste containing lidocaine and prilocaine, and a saline cornual block; cornual block (B), commercial caustic paste and a lidocaine cornual nerve block; and positive $(\mathrm{P})$, commercial caustic paste and a saline cornual block. All calves received $0.5 \mathrm{mg} / \mathrm{kg}$ of meloxicam $\mathrm{SC}$ at the time of the block. Researchers were blinded to treatment group. Primary outcomes were validated pain behavior responses and pain sensitivity measured by algometry. Secondary outcomes consisted of respiratory and heart rate, latency to approach the evaluator, play behavior, feeding behavior, and standing and lying bout characteristics. Data were analyzed using linear, Poisson, and negative binomial regression models. Cornual-blocked calves had less pain sensitivity to $180 \mathrm{~min}$ after disbudding than all other groups; $\mathrm{T}$ and $\mathrm{P}$ calves had more pain sensitivity than $\mathrm{S}$ calves for the same time period. Compared with $\mathrm{T}$ and $\mathrm{P}$ calves, $\mathrm{B}$ and $\mathrm{S}$ calves had fewer pain behaviors until 120 min postdisbudding,
\end{abstract}

Received February 13, 2017.

Accepted April 3, 2017.

${ }^{1}$ Corresponding author: tduffiel@uoguelph.ca decreased respiratory and heart rates, and a shorter latency to feed. The $\mathrm{S}$ calves exhibited more play behavior than other groups. Caustic paste appears to be acutely painful for at least $180 \mathrm{~min}$, and this is reduced by a cornual nerve block but not by our novel paste. Because caustic paste may result in a different pain experience than cautery, use of a variety of metrics assessing affective state, physiologic responses, and normal behaviors, such as feeding and lying, should be included into future trials to help assess the welfare of calves disbudded by this method. We recommend that calves disbudded with caustic paste receive local anesthetic with a cornual nerve block as well as a nonsteroidal anti-inflammatory drug to mitigate acute pain.

Key words: disbudding, pain, caustic paste, calves

\section{INTRODUCTION}

Disbudding or dehorning of dairy calves is considered necessary for the safety of both humans and cattle (Stock et al., 2013). Dehorning refers to the removal of the horn after attachment of the horn bud to the skull, occurring at approximately 2 mo of age (CVMA, 2010; AVMA, 2014). Although polled genetics have been introduced for all major dairy breeds, the use of polled dairy sires in Canada is low (Winder et al., 2016).

Evidence exists that disbudding is less painful than dehorning (Petrie et al., 1996; Stilwell et al., 2007). In Canada, veterinary and industry groups have recommended that disbudding be performed at less than 2 (CVMA, 2010) or 3 wk of age (National Farm Animal Care Council, 2009; Dairy Farmers of Canada, 2015), although no published peer-reviewed literature supports such cut-points. A large body of work has shown benefits of both local anesthesia and systemic analgesia for surgical amputation or cautery methods of disbudding or dehorning (Stafford and Mellor, 2011; Stock et al., 2013). The use of pain control for disbudding or dehorning has been recommended by many veterinary groups (CVMA, 2010; AVMA, 2014). The European Union has legislated that local anesthesia be provided 
to animals disbudded or dehorned over $4 \mathrm{wk}$ of age, but there is no requirement for animals less than 4 wk old (European Commission, 1988). In Canada, pain control for dehorning will be an industry requirement for all dairy producers beginning in September 2017 (Dairy Farmers of Canada, 2015).

Although less common than hot-iron disbudding, chemical disbudding, done by use of caustic paste or stick, is also used by dairy producers throughout the world (Adams et al., 2015; Cozzi et al., 2015; Winder et al., 2016). Chemical disbudding uses a very alkaline substance (typically sodium or calcium hydroxide with a $\mathrm{pH}$ of 14) to cause a chemical burn, effectively destroying the germinal tissue of the horn bud. This disbudding method is used in $13 \%$ of dairy operations in Ontario (Winder et al., 2016) and $16 \%$ of those in the United States (Adams et al., 2015). Although the use of caustic paste is recommended by manufacturers at less than 1 wk of age, the mean age of caustic paste use in the United States is 2.3 wk (Adams et al., 2015), and $24 \%$ dairy producers in Ontario using caustic paste apply this at more than 4 wk of age (Winder et al., 2016). In the United Kingdom, caustic paste use is restricted to use under 1 wk of age (Stafford and Mellor, 2005), and in New Zealand in Canada industry codes recommend use at less than 7 to $10 \mathrm{~d}$ of age (New Zealand National Animal Welfare Advisory Committee, 2005; Dairy Farmers of Canada, 2015).

Caustic paste disbudding has been associated with reduced adoption of producer-use of pain control (Winder et al., 2016). Six percent of US producers using caustic paste reported using pain control, compared with $30 \%$ for those disbudding with a hot iron (Adams et al., 2015). Although strong evidence exists on the benefit of local anesthesia and systemic analgesia for hot-iron disbudding or surgical amputation dehorning (Stafford and Mellor, 2011; Stock et al., 2013), best practices to control the pain of caustic paste disbudding remain unclear. The nature, duration, and intensity of the pain caused by a chemical burn is likely different than that of a thermal burn (Bromberg et al., 1965).

The utility of local anesthesia for caustic paste disbudding has been disputed; some work has shown an initial benefit (Morisse et al., 1995; Stilwell et al., 2009), which extends past the first hour if a nonsteroidal antiinflammatory drug (NSAID) is also given (Stilwell et al., 2009). However, in heavily sedated calves (0.2 $\mathrm{mg} / \mathrm{kg}$ of xylazine IV), Vickers et al. (2005) found no observed benefit to giving local anesthetic using a ring block. The use of a lidocaine cornual nerve block, some distance from the horn bud, with a volume of 4 to $5 \mathrm{~mL}$ per side, would likely be a more appropriate method of generating local anesthesia for caustic paste disbudding. Stilwell et al. (2008) showed that an NSAID given alone was not sufficient to control the acute pain of caustic paste disbudding, and the use of an opiate alone was similarly ineffective (Braz et al., 2012).

Despite the lack of robust evidence, caustic paste disbudding has been suggested to be one of the least painful methods for horn bud removal (Vasseur et al., 2010; Von Keyserlingk and Weary, 2015). Caustic paste disbudding has been promoted to dairy producers in farm publications as a method that does not require use of pain control (Villarroel, 2010), with manufacturer claims that it is "less painful than hot-iron disbudding" (H.W. Naylor Co. Inc., 2015). These conclusions differ from a literature review by Stock et al. (2013), which suggests that, without the provision of analgesics, cautery be used over chemical methods based on the lack of peer-reviewed research. Stafford and Mellor (2011) argue that the lack of an initial reaction of the calf during application may give a false impression of the pain associated with the procedure. Our objective was to examine the efficacy of 2 pain-control strategies for the acute pain of caustic paste disbudding: a lidocaine cornual nerve block and a novel caustic paste containing lidocaine and prilocaine.

\section{MATERIALS AND METHODS}

\section{Animal Use}

This trial was conducted between January and May of 2016 at the University of Guelph Dairy Research and Innovation Center. Use of animals and all methods for this study were approved by the University of Guelph Animal Care Service in compliance with animal use guidelines (AUP\#1965) of the Canadian Council on Animal Care (1993).

\section{Housing and Management}

Calves were housed in individual rooms containing a single group pen $(9 \times 5 \mathrm{~m})$ with up to 15 animals per room or pen. Bedding was wood shavings, which was cleaned daily and replaced weekly. Individual pens (2.3 $\mathrm{m}^{2}$ ) were constructed with gates on the perimeter of the group pen for use during each trial day; these pens were the same pens the staff used to house all calves from birth until entry into the group pen at approximately 3 to $5 \mathrm{~d}$ of age. Male and female Holstein calves were used; male calves were kept on the farm for at least 20 d after enrollment in the trial and female calves were kept on the farm as replacement animals. At birth, calves were vaccinated intranasal against viral respiratory pathogens (Inforce 3, Zoetis, Kirkland, Quebec, Canada) and navels were dipped with $2.5 \%$ povidoneiodine. Calves were moved out of the calf rooms and 
into a pen in the freestall barn at 9 wk of age. Calf coats were worn by calves during the first 3 wk of age during colder weather; these coats were removed during the trial period in individual pens but were replaced when calves re-entered the group pen.

\section{Nutrition}

After birth and colostrum feeding, calves were moved into individual pens and manually fed $2 \mathrm{~L}$ of milk replacer by bottle 3 times a day until sucking well (typically 3 to $5 \mathrm{~d}$ ), after which they were placed into the group pen and introduced to the automated milk feeder (VARIO smart, Förster-Technik, Engen, Germany). Calves were given access to $2 \mathrm{~L}$ of milk replacer every $2 \mathrm{~h}$ with no daily limit for the first $7 \mathrm{~d}$ on the feeder, with meal size increasing to $2.5 \mathrm{~L}$ from 7 until $21 \mathrm{~d}$, and $3 \mathrm{~L}$ per meal thereafter. Daily restrictions began at 27 $\mathrm{d}$, with a 12-L limit at $27 \mathrm{~d}$ on the feeder, decreasing to $9 \mathrm{~L}$ per day at $32 \mathrm{~d}$, and staying at this level until 42 d. After $42 \mathrm{~d}$, this level was slowly decreased to reach $0 \mathrm{~L}$ by $56 \mathrm{~d}$. Calves also had use of an automated grain feeder (Förster-Technik) providing ad libitum access to $22 \%$ CP calf starter pellets, buckets of finely chopped wheat straw, and a single water bowl per pen.

\section{Enrollment}

All calves born on the university research farm during the trial period were eligible for the study, provided they had no abnormal findings on a physical exam by a veterinarian on the initial study day and that they were not currently being treated for illness by the farm staff. Three calves were not enrolled; 2 were being treated for respiratory disease and the third had an audible heart murmur.

Eighteen replicates were completed on separate days, with approximately 1 replicate per week. Each replicate consisted of 4 calves balanced by age and assigned to 1 of the 4 treatment groups, with every replicate containing all 4 treatments. Seventy-two calves were enrolled in the trial, with 18 calves in each treatment group.

\section{Treatment Groups}

The 4 treatment groups were a positive control $(\mathbf{P})$, a negative sham control (S), a cornual block $(\mathbf{B})$, and a novel product containing local anesthetic in the caustic paste $(\mathbf{T})$. The $\mathrm{P}$ calves were given a saline cornual nerve block $(5 \mathrm{~mL}$ per side, sodium chloride injection USP 0.9\%, Bimeda-MTC Animal Health Inc., Cambridge, Ontario, Canada), $0.5 \mathrm{mg} / \mathrm{kg}$ of meloxicam SC (Metacam $20 \mathrm{mg} / \mathrm{mL}$ Solution for Injection, Boehringer Ingelheim, Burlington, Ontario, Canada), and disbudded with commercial caustic paste (Dr. Naylor Dehorning Paste, H.W. Naylor Co. Inc., Morris, NY). The $\mathrm{S}$ calves were given a saline cornual nerve block and meloxicam, as described above, and sham disbudding paste was applied (OmniVet Pharma Inc./Philco Animal Health Inc., Kitchener, Ontario, Canada); these calves were not disbudded during the study. The $\mathrm{C}$ calves were given a lidocaine cornual nerve block $(5 \mathrm{~mL}$ per side, lidocaine $\mathrm{HCl} 2 \%$ with epinephrine injection USP, Bimeda-MTC), meloxicam as described above, and disbudded with commercial caustic paste. The $\mathrm{T}$ calves were given a saline cornual nerve block and meloxicam, as described above, and were disbudded with a novel caustic paste compound containing $2.5 \%$ lidocaine and $2.5 \%$ prilocaine constituted by OmniVet Pharma Inc./Philco Animal Health Inc. Cornual nerve block technique was done by insertion of an 18-gague, $35-\mathrm{mm}$ needle caudal to the eye, ventral to the temporal ridge, with the injection of $5 \mathrm{~mL}$ per side fanned out in 3 directions. A full description of the technique is available online (http://bit.ly/disbudding).

\section{Primary Outcomes}

Algometry. Pain sensitivity was measured using a pressure algometer (Force Ten FDX 50, Wagner Instruments, Greenwich, CT) following the protocol described by Heinrich et al. (2010), with a modification that calves in our trial were restrained tightly and the recorded reading was measured when the calf tugged against the restraint. Readings were taken at 4 points equidistant around each horn bud. The algometer was first placed lightly on the area before force was applied; calves with immediate reactions were retested in the same site to better ensure accuracy of readings. Minimum values recorded by algometry were $0.5 \mathrm{~kg}$ of force (kgf) and the maximum was $5.0 \mathrm{kgf}$. Values for each of the 8 sites were averaged to give a single value per calf for analysis. The same evaluator measured algometry and all other measures for all calves in our trial.

Pain Behavior. A standard pain behavior ethogram was used, which consisted of ear flick, head shake, head rub, tail flick, foot stamp, and vocalization (Faulkner and Weary, 2000; Milligan et al., 2004; Heinrich et al., 2010). Ear flicking was defined as the movement of one or both ears front and back, independent of a head shake; an ear flick stopped and the next one could start when the ears were at resting position. A head shake was defined as a rapid movement laterally of the head, which stopped when the head was in resting position. Head rubbing was defined as the use of the calf's hind leg or any part of the pen to scratch the top of its head, and stopped when the calf's leg was back on the ground or when the calf stopped rubbing against the pen. Tail 
flicking was defined as a lateral, rapid movement of the tail, and a new tail flick only began when the tail was in resting position. Foot stamping was defined as a raising and quick, firm bringing down of any limb. Each calf was evaluated individually for a period of $2 \mathrm{~min}$ for each observation period and behaviors were recorded live by the evaluator. A second observer was present at 1 trial replicate to determine the level of interobserver agreement.

\section{Secondary Outcomes}

Heart and Respiratory Rate. The evaluator assessed respiratory rate by observing the flank without entering the pen or disrupting the calf. Heart rate was assessed by auscultation after restraining the calf with a halter and was done before algometry.

Feed Consumption and Feeding Behavior. Data from the automated milk feeder were imported to Microsoft Excel (Microsoft Corp., Redmond, WA). Baseline data were defined as values for the 24-h period before the trial day, and data from the trial day and the day after the trial were examined separately. Variables examined consisted of total milk consumed, average drinking speed, number of break-offs from the feeder, number of rewarded feeder visits, number of unrewarded feeder visits, and latency to consume milk from the feeder after re-entry to the group pen (only on the day of the trial).

Standing and Lying Bouts. We used HOBO Pendant $\mathrm{G}$ data loggers (Onset Computer Corp., Bourne, MA) set with a $60 \mathrm{~s}$ recording interval, which have been validated as a measure of lying behavior in dairy calves (Bonk et al., 2013). Loggers were attached vertically to the right rear leg with a cohesive bandage before re-entry to the group pen, and were removed 24 $\mathrm{h}$ after disbudding. Data were imported into Microsoft Excel (Microsoft Corp.) and y-axis values were manually examined with values of less than -0.8 indicating standing and values of more than -0.2 indicating lying. The number of standing or lying bouts, total time spent lying or standing, and average lying or standing bout length were calculated.

Play Behavior and Grooming. During a 10-min live observation period immediately following re-entry the group pen, play behaviors were recorded by the evaluator. Play behaviors consisted of run, buck, and head-to-head contact, as described by Mintline et al. (2013). Run was any gait faster than a walk, and stopped when the calf resumed walking or halted. Buck was described as a movement when both hind hooves are lifted off the ground where the legs may be kicked outwards. Head-to-head contact was any contact between the head or neck of 2 calves for $1 \mathrm{~s}$ or longer, which stopped when the calves no longer had contact. Self-grooming behaviors were recorded during the multiple 2-min pain behavior assessments, as described above. A second observer was present at 1 trial replicate to determine the level of interobserver agreement for both play and grooming behaviors.

Latency to Approach. Latency of calves to approach the evaluator was assessed by entering the pen, closing the gate, and standing quietly at the gate without looking directly at the calf. Time from gate closure to first contact of the calf's nose to any part of the evaluator was recorded, up to a maximum of $180 \mathrm{~s}$.

Regrowth. For female calves ( $\mathrm{n}=32,44 \%$ of calves), horn bud regrowth was monitored by farm staff after weaning and reported back to the researchers. Regrowth was classified as either a scur or horn, based on attachment to the base of the skull and external appearance. Regrowth was considered as an outcome because we wanted to ensure the inclusion of local anesthetic agents into the modified caustic paste did not alter the product's efficacy.

\section{Data Collection}

On the day of the experimental treatment, calves were temporarily moved from the group pen to individual pens. Calves in the individual pens were able to see each other as well as the remaining calves left in the group pen, and were able to have direct contact through the pen gates with both the group pen and neighboring individual pens. Each individual pen had a water bucket but did not have access to feed. Calves were held in individual pens for a total of $4 \mathrm{~h}$ before returning to the group pen. Calves were given $1 \mathrm{~h}$ to acclimatize to the individual pen before disbudding occurred; upon entry, hair was clipped with bandage scissors and a physical exam was performed. Algometry was done after the physical exam to habituate calves to the device. At 30 min after pen entry, a 2-min observation period of pain behaviors and respiratory rate were performed, after which baseline latency to approach was measured. At $15 \mathrm{~min}$ before disbudding, another 2-min observation period was done for each calf to establish baseline pain behaviors and respiratory rate. Calves were then halter tied, baseline heart and algometry readings were taken, and the saline or lidocaine cornual nerve blocks and meloxicam were given. Fifteen minutes later, disbudding was performed by applying a ring of petroleum jelly around the horn bud (to protect the calf from spread of the caustic paste), and a thin layer of caustic paste was then applied to the horn bud with a tongue depressor. The area covered was the horn bud and a small ring of tissue surrounding the horn bud; older calves had larger horn buds and, therefore, 
a larger area was covered. Two-minute observation periods for pain behaviors, grooming behaviors, and respiratory rate were then taken at $15,30,45,60,90$, 120, and $180 \mathrm{~min}$ after disbudding. At $90 \mathrm{~min}$, latency to approach was assessed. Calves were halter-tied and heart rate and algometry readings were taken at 60 , 120, and $180 \mathrm{~min}$, after the 2-min behavior and respiratory rate observation period. At $180 \mathrm{~min}$, HOBO data loggers were placed on the rear right leg with a cohesive bandage and calves were let back into the group pen. After all calves were allowed into the group pen, play behavior was assessed for a 10-min period. At $24 \mathrm{~h}$ after disbudding, calves were halter-tied, HOBO data loggers were removed, and final algometry readings were taken.

If calves had any paste smeared on other parts of their head, legs, body, or on parts of the pen during the first 180 min after disbudding, this was wiped from the calf or pen with distilled vinegar (5\% acetic acid) when the calf was next halter-tied, and after all measures were taken for that time period. No paste was further applied after initial application.

\section{Sample Size}

A sample size calculation was done a priori considering algometry as the primary outcome. This was based on a difference in estimated mean of $2.5 \mathrm{kgf}$ compared with $2.0 \mathrm{kgf}$ for pain sensitivity of treatment groups (B and $\mathrm{T}$ calves) compared with $\mathrm{P}$ calves, based on findings from Heinrich et al. (2010), with a standard deviation of $0.5 \mathrm{kgf}, 95 \%$ confidence, and $80 \%$ power. This value was then rounded up by 2 per group to account for possible post hoc exclusions, resulting in culmination of the study after 18 replicates were completed.

\section{Treatment Allocation and Blinding}

Calves in our study ranged from 2 to $32 \mathrm{~d}$ of age; calf age was considered as a potential confounding variable for the primary outcomes. Thus, eligible calves in each replicate were ordered by age and placed into the 4 treatment groups using premade sheets, with the first replicate order of treatments randomly assigned and subsequent replicates with the order of treatments changing down by one per replicate (i.e., if the oldest calf in the first replicate received treatment 2 , the next oldest calf would receive treatment 3 , and so on; then, in the second replicate the oldest calf would receive treatment 3 , and the next oldest treatment 4 , and so on). A research technician, separate from the evaluator, was responsible for assigning calves to treatment groups and communicating this to the evaluator. The research technician randomly assigned each of the 4 treatments to a blinded treatment name (treatments
$1,2,3$, and 4), and concealed the caustic paste type ( 2 jars of commercial paste, 1 sham, and 1 novel paste containing lidocaine) by wrapping cohesive bandage around the containers and marking them as treatment 1, 2, 3 or 4. Except for treatment number, containers were identical between treatments. Lidocaine or saline cornual nerve blocks were drawn up into syringes $(2$ per calf) ahead of each replicate by the research technician, and both the syringes and paste containers were placed in a container marked for each treatment group, which were then delivered to the evaluator. There was no visible difference between saline- or lidocaine-filled syringes. Staff on the farm responsible for the care of the calves were also blinded to treatment groups. The researchers remained blinded to the treatment groups during data analysis.

\section{Statistical Analysis}

The evaluator used paper records, which were then entered into Microsoft Excel (Microsoft Corp.) and exported into STATA13 (Stata/IC Version 13.1 for Mac, StataCorp, College Station, TX). Descriptive statistics were reviewed and all continuous data (respiratory rate, heart rate, pain behavior, feed consumption, and latency to approach) were assessed for normality. Pain behaviors were examined individually for the most common behaviors observed (head shake, head rub, tail flick), and those with no observed or few observed $(<5 \%)$ behaviors were discarded from further analysis (ear flick, foot stamp, and vocalization).

For outcomes with repeated measures (algometry, pain behaviors, heart rate and respiratory rate, grooming), a mixed model for each outcome was built with baseline data as a covariate and calf as a random effect. For continuous, normally distributed data (algometry, heart and respiratory rate) a linear model was used, and for count data (head rub, head shake, tail flick, groom, and a sum of the 3 pain behaviors) Poisson and negative binomial models were built, with the negative binomial model used if the over-dispersion term was significant. The effect of treatment on outcome was tested, as well as a first-order interaction term for treatment by time. Significant treatment by time interactions were found for all models, and therefore the effect of treatment on outcome was stratified by time, with single-level models used for each time point.

For point in time outcomes (feed consumption, standing and lying bouts, play behavior, latency to approach, and horn regrowth), single-level models were used. For continuous data (total milk consumed, average drinking speed, latency to feed, total time spent standing or lying, average time spent standing or lying, and latency to approach the evaluator), linear regression models 
were used with a fixed effect for baseline data for total milk consumed, average drinking speed, and latency to approach the evaluator outcomes. For count outcomes (number of breakoffs, number of rewarded feeder visits, number of unrewarded visits, number of standing or lying bouts, and total play behaviors), both Poisson and negative binomial models were built, with fixed effects used for baseline data for number of breakoffs and number of rewarded and unrewarded feeder visits. The negative binomial model was used if the over-dispersion term was significant. Zero-inflated models were built if there was a large number of zero counts in the data. For all models, the effects of age (in days), sex, and first-order interaction terms between treatment and age, and treatment and sex, were offered to the model and retained if significant.

Head rubs, head shakes, and tail flicks were the most commonly seen pain-associated behaviors; foot stamps were not seen, and vocalization and ear flicks were seen in less than $5 \%$ of calves. For the former 3 behaviors, counts typically were between 0 and 10 for each 2 -min observation period. A similar pattern of treatment effect on mean number of behaviors at each time point was seen for all 3 pain behaviors, but there were many time points where the sham group had means of zero behaviors. Zero inflated negative binomial models were either unstable or did not converge. To capture the essence of the data, the 3 behaviors were summed to generate a total of pain behaviors which was then analyzed.

Although only 1 person conducted the evaluations for this trial, we added a second observer for 1 replicate to determine interobserver agreement for pain, grooming, and play behaviors; this was determined by generating Spearman's rank correlation coefficient for each of the outcomes [head rub, head shake, tail flick, groom, and total play behaviors (run, buck, and head-to-head contact)]. The level of agreement was considered acceptable if the Spearman's rank value was greater than 0.90. This was done to better determine the validity and reproducibility of the behavioral recording.

\section{RESULTS}

\section{Age and Sex}

Calf age ranged from 2 to $32 \mathrm{~d}$ on the day of disbudding, and mean age $(16 \pm 0.8 \mathrm{~d})$ did not differ significantly between groups. Thirty-two female calves and 40 male calves were used.

\section{Primary Outcomes}

Algometry. Mean baseline algometry scores before treatment were not significantly different by treatment group $(2.8 \pm 0.1 \mathrm{kgf})$. We found no significant effect of age or sex on algometry scores. Algometry scores by treatment group over time are described in Figure 1. At 60 min after paste application, B calves had a mean score of $4.4 \mathrm{kgf}(\mathrm{SE}=0.2)$, higher than all other groups $(P<0.001)$. The $\mathrm{T}(1.0 \mathrm{kgf}, \mathrm{SE}=0.1)$ and $\mathrm{P}(1.0 \mathrm{kgf}$, $\mathrm{SE}=0.2)$ calves were lower than $\mathrm{S}$ calves $(2.0 \mathrm{kgf}$, SE $=0.1 ; P<0.001)$ for this time point. This effect continued to $120 \mathrm{~min}$ (B calves $=3.7 \mathrm{kgf}, \mathrm{SE}=0.3 ; \mathrm{S}$ calves $=1.8 \mathrm{kgf}, \mathrm{SE}=0.1 ; \mathrm{T}$ and $\mathrm{P}$ calves $=0.9 \mathrm{kgf}, \mathrm{SE}=$ 0.1 ) and $180 \mathrm{~min}(\mathrm{~B}$ calves $=3.0 \mathrm{kgf}, \mathrm{SE}=0.3 ; \mathrm{S}$ calves $=1.9 \mathrm{kgf}, \mathrm{SE}=0.1 ; \mathrm{T}$ calves $=1.0 \mathrm{kgf}, \mathrm{SE}=0.1 ; \mathrm{P}$ calves $=0.8 \mathrm{kgf}, \mathrm{SE}=0.1$ ). At $24 \mathrm{~h}$ postdisbudding, mean scores were similar, with $\mathrm{T}$ calves tending to have lower scores than $\mathrm{B}$ or $\mathrm{S}$ calves $(P<0.10$; $\mathrm{B}$ calves $=$ $2.1 \mathrm{kgf}, \mathrm{SE}=0.2 ; \mathrm{S}$ calves $=2 \mathrm{kgf}, \mathrm{SE}=0.1 ; \mathrm{P}$ calves $=1.9 \mathrm{kgf}, \mathrm{SE}=0.1 ; \mathrm{T}$ calves $=1.6 \mathrm{kgf}, \mathrm{SE}=0.1$ ).

Pain Behaviors. Head rubs, head shakes, and tail flicks were the most commonly seen pain-associated behaviors; foot stamps were not seen and vocalization and ear flicks were seen in less than $5 \%$ of calves. For the former 3 behaviors, counts typically were between 0 and 10 for each 2-min observation period. We found no significant effect of age or sex on pain behaviors; the total of these 3 pain behaviors is presented in Figure 2. At 15 min after caustic paste application, $\mathrm{P}$ and $\mathrm{T}$ calves showed more pain behaviors $(P<0.001)$ than $\mathrm{S}$ or $\mathrm{B}$ calves $(\mathrm{P}$ calves $=9.9, \mathrm{SE}=1.8 ; \mathrm{T}$ calves $=7.7$, $\mathrm{SE}=1.8 ; \mathrm{B}$ calves $=0.3, \mathrm{SE}=0.2 ; \mathrm{S}$ calves $=0.2, \mathrm{SE}$ $=0.2$ ). This effect of $\mathrm{P}$ and $\mathrm{T}$ calves showing more pain behaviors than $\mathrm{S}$ or $\mathrm{B}$ calves was similar at $30(P<$ $0.001), 45(P<0.001)$, and $60 \mathrm{~min}(P<0.05)$. At 120 and $180 \mathrm{~min}$, mean pain behaviors were not different by treatment group.

\section{Secondary Outcomes}

Heart Rate. Mean initial heart rate $(128 \pm 2$ beats per minute) did not differ by group. We noted no effect of age or sex on heart rate. Differences in mean heart rate by treatment group over time are presented in Figure 3. At 60 min after paste application, pulse rate was higher for $\mathrm{P}(164, \mathrm{SE}=6)$ and $\mathrm{T}(162, \mathrm{SE}=8)$ calves compared with $\mathrm{S}(122, \mathrm{SE}=6 ; P<0.001)$ and $\mathrm{B}(132$, $\mathrm{SE}=4 ; P<0.01)$ calves; $\mathrm{B}$ calves tended to be higher than $\mathrm{S}$ calves $(P<0.10)$. At $120 \mathrm{~min}$, T calves $(157, \mathrm{SE}$ $=5)$ were higher than $\mathrm{B}(129, \mathrm{SE}=6)$ or $\mathrm{S}(120, \mathrm{SE}$ $=5)$ calves $(P<0.01)$, and not different from $\mathrm{P}$ calves $(151, \mathrm{SE}=8)$. The $\mathrm{P}$ calves had higher pulse rates than $\mathrm{S}$ calves $(P<0.01)$, but only tended to be higher than B calves $(P<0.10)$. At $180 \mathrm{~min}$, we observed no statistical differences between $\mathrm{P}(150, \mathrm{SE}=4), \mathrm{T}(140$, $\mathrm{SE}=7)$, or $\mathrm{B}(137, \mathrm{SE}=5)$ calves, and these 3 groups were all higher than $\mathrm{S}$ calves $(122, \mathrm{SE}=5 ; P<0.05)$. 
Respiratory Rate. Mean initial respiratory rate (36 \pm 1 breaths per minute) did not differ by group. We found no effect of age or sex on respiratory rate. Mean differences in respiratory rate by treatment group are presented in Figure 4. At 15 min after paste application, respiratory rate was higher in $\mathrm{P}(46, \mathrm{SE}=3)$ and $\mathrm{T}(38, \mathrm{SE}=2)$ calves compared with $\mathrm{S}(32, \mathrm{SE}=2)$ or $\mathrm{B}(32, \mathrm{SE}=2)$ calves $(P<0.05)$. This effect was similar at 30 and $45 \mathrm{~min}$, with $\mathrm{P}$ and $\mathrm{T}$ calves having higher respiratory rates than $\mathrm{S}$ or $\mathrm{B}$ calves $(P<0.05)$. By $60 \mathrm{~min}, \mathrm{P}(45, \mathrm{SE}=3)$ and $\mathrm{T}(38, \mathrm{SE}=3)$ calves were higher than $\mathrm{S}(31, \mathrm{SE}=2)(P<0.05)$, with $\mathrm{B}(36$, $\mathrm{SE}=3)$ calves having a lower respiratory rate than $\mathrm{P}$ calves $(P<0.05)$ but not differing statistically from $\mathrm{S}$ or $\mathrm{T}$ calves.

Feed Consumption and Feeding Behavior. Milk feeder data were missing for 7 calves; results are presented for the remaining 65 calves. No statistical differences in total amount consumed, average drinking speed, number of milk feeder breakoffs, or number of rewarded or unrewarded visits were seen by treatment group for either the day of disbudding or the following 24-h period. Milk consumption was not different by day, with a mean of $10 \mathrm{~L}$ consumed $(\mathrm{SD}=3 \mathrm{~L})$ per day. Mean number of rewarded visits was $8 \pm 0.4$ over the $3 \mathrm{~d}$, with mean $2 \pm 0.4$ unrewarded visits per day. Latency to feed was measured following introduction back into the group pen at 180 min after disbudding. The $\mathrm{S}$ calves mean time to drink $(16 \pm 4 \mathrm{~min})$ was not statistically different $(P=0.31)$ from B calves $(40 \pm 16$ min), but $\mathrm{S}$ calves tended to drink sooner than $\mathrm{T}(58 \pm$ $22 \mathrm{~min})$ or $\mathrm{P}(60 \pm 17 \mathrm{~min})$ calves $(P<0.10)$.

Standing and Lying Behavior. For the time period between entry into the group pen and $24 \mathrm{~h}$ after disbudding, no statistical differences were seen between treatment groups for number of standing or lying bouts, total time spent standing or lying, or percentage of time spent standing or lying. Calves had a mean of $17 \pm 0.5$ lying bouts, with $74 \%$ of their time spent lying.

Play Behavior. For the 10-min observation period after re-entry into the group pen, $\mathrm{S}$ calves had more play behaviors $(9.2 \pm 2.0)$ than other groups $(\mathrm{B}=4.1$

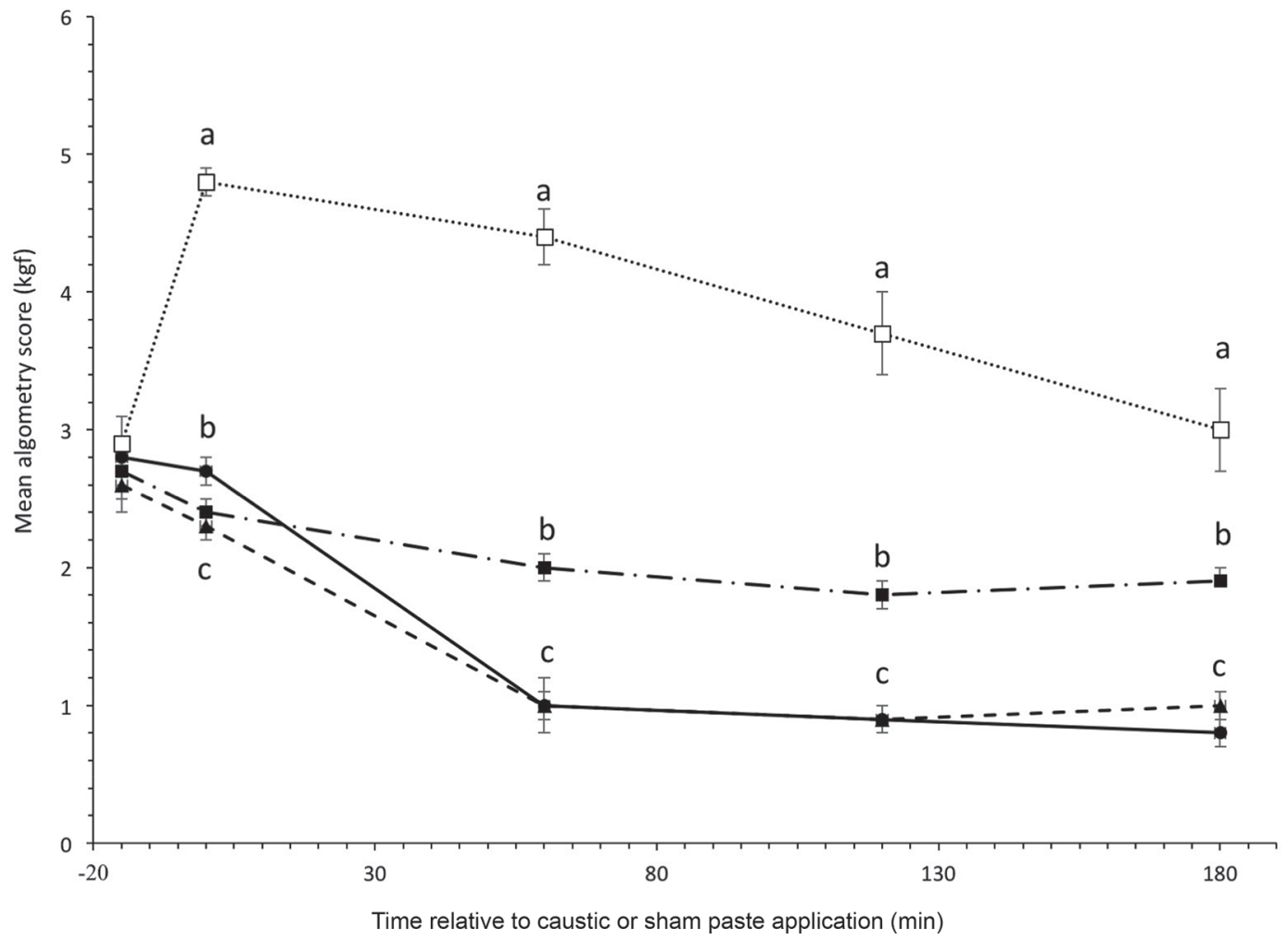

Figure 1. Mean $( \pm \mathrm{SE})$ algometry score relative to disbudding with caustic or sham paste. Positive control group (commercial caustic paste and saline cornual nerve block; solid line with closed circular markers); topical anesthetic delivered in a novel caustic paste (novel caustic paste containing $2.5 \%$ lidocaine and $2.5 \%$ prilocaine, and saline cornual block; dashed line with closed triangular markers); cornual nerve block [commercial caustic paste and $5 \mathrm{~mL}$ per side lidocaine (with epinephrine) cornual nerve block; dotted line with open square markers]; and sham group (placebo paste and saline cornual nerve block; dashed and dotted line with closed square markers). All groups received the saline or lidocaine cornual nerve block as well as injectable meloxicam $(0.5 \mathrm{mg} / \mathrm{kg}$ subcutaneously) at $15 \mathrm{~min}$ before disbudding. Different letters (a-c) reflect differences between treatment groups $(P<0.05)$ for a single time point. 
$\pm 1.2 ; \mathrm{P}=3.8 \pm 1.6 ; \mathrm{T}=3.3 \pm 1.6 ; P<0.001)$, and younger calves also played more $(-1.0 \pm 0.2$ play behaviors per increase of $10 \mathrm{~d}$ of age; $P<0.001$ ).

Grooming Behavior. Grooming behaviors were infrequent; less than half the calves displayed grooming behaviors at any time point. No effect of age or sex was seen on grooming behavior. The number of grooming behaviors in each 2-min observation window ranged from 0 to 5 . At 15 min after paste application, $\mathrm{T}$ calves $(1.0, \mathrm{SE}=0.3)$ had more self-grooming behaviors than $\mathrm{S}(0.2, \mathrm{SE}=0.1)$ or $\mathrm{B}(0.1, \mathrm{SE}=0.1)$ calves $(P<0.01)$. The $\mathrm{P}$ calves $(0.5, \mathrm{SE}=0.2)$ had more grooming than $\mathrm{B}$ calves $(P<0.05)$ and tended to have more than $\mathrm{S}$ calves $(P<0.10)$. At 30 min after paste application, $\mathrm{P}$ calves $(0.5, \mathrm{SE}=0.2)$ tended to have more grooming behaviors than $\mathrm{B}$ calves $(0.2, \mathrm{SE}=0.2)$ but were not different from $\mathrm{T}$ calves $(0.3, \mathrm{SE}=0.2)$. No $\mathrm{S}$ calves showed grooming behavior at this time point. After $30 \mathrm{~min}$, grooming behaviors were less frequent (group means of $0-0.2$ per 2-min observation period) and no statistical differences were seen between groups $(P>$ $0.10)$.

Latency to Approach. Baseline latency to approach the evaluator was $81 \pm 9 \mathrm{~s}$, whereas latency to approach at $90 \mathrm{~min}$ after paste application was $125 \pm$ $8 \mathrm{~s}(\mathrm{SD}=68)$. No differences were seen between treatment groups.

Regrowth. Regrowth after weaning was seen unilaterally in 6 calves (of 32 heifers, 20\%), and all were determined to have scurs as opposed to full horn growth. One calf was from treatment P, 2 from treatment B, and 3 from treatment $\mathrm{T}$.

\section{Interobserver Agreement}

Spearman rank correlation coefficient values were 0.96 for grooming behavior, 1.00 for head rubbing, 0.96 for head shake, 0.92 for tail flick, and 1.00 for play behavior (run, buck, and head-to-head contact).

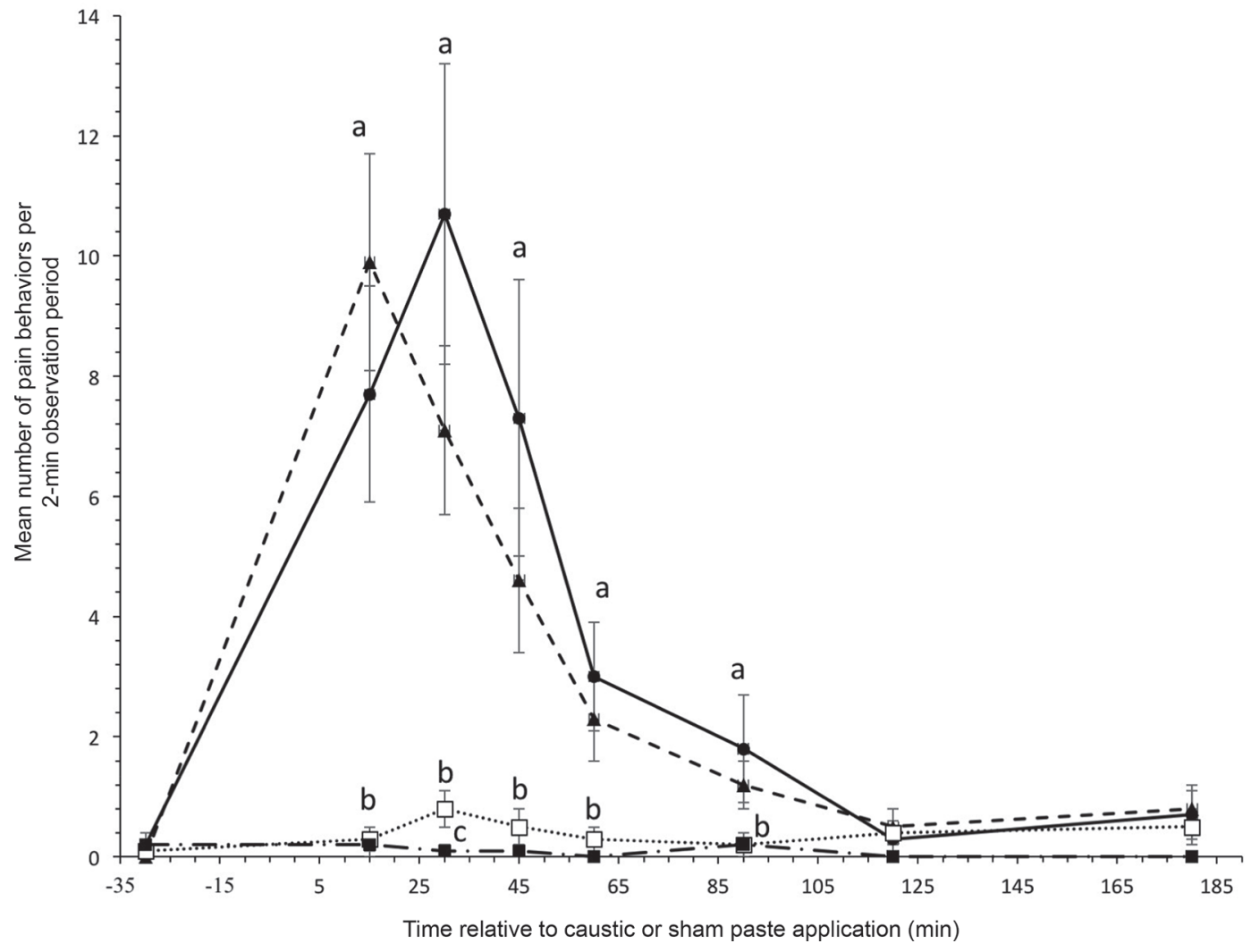

Figure 2. Mean $( \pm \mathrm{SE})$ total pain behaviors (head shake, head rub, or tail flick) in a 2-min observation period by treatment group with SE bars plotted by time in minutes relative to disbudding with caustic or sham paste. Positive control group (commercial caustic paste and saline cornual nerve block; solid line with closed circular markers); topical anesthetic delivered in a novel caustic paste (novel caustic paste containing $2.5 \%$ lidocaine and $2.5 \%$ prilocaine, and saline cornual block; dashed line with closed triangular markers); cornual nerve block [commercial caustic paste and $5 \mathrm{~mL}$ per side lidocaine (with epinephrine) cornual nerve block; dotted line with open square markers]; and sham group (placebo paste and saline cornual nerve block; dashed and dotted line with closed square markers). All groups received the saline or lidocaine cornual nerve block as well as injectable meloxicam $(0.5 \mathrm{mg} / \mathrm{kg}$ subcutaneously) at $15 \mathrm{~min}$ before disbudding. Different letters (a-c) reflect differences between treatment groups $(P<0.05)$ for a single time point. 


\section{Adverse Events}

A 21-d-old female calf from treatment group B developed a mild conjunctivitis after rubbing the caustic paste into her eye at $30 \mathrm{~min}$ after disbudding; this was wiped from the skin near the eye and the eye flushed immediately. Interestingly, the calf had exhibited only 2 head rub behaviors at this time point (in contrast, several calves exhibited up to 10 or more behaviors in 1 observation period without causing harm to themselves). At the next observation time point (45 min) the calf exhibited no head rub or shake behaviors. The conjunctivitis resolved within $24 \mathrm{~h}$.

\section{DISCUSSION}

To avoid a potential confounding effect of age with treatment, we assembled replicates to balance on age by sequential allocation that shifted between replicates. Although not completely randomized, we maintain our inferences are representative, as there was no predictability on treatment the calf was assigned. The research team also remained blinded to treatment allocation during both the study and data analysis.

We found that, without the provision of local anesthetic and analgesia, caustic paste disbudding is acutely painful for at least $3 \mathrm{~h}$ following application, similar to previous findings (Morisse et al., 1995; Stilwell et al., 2008). The use of a 5-mL lidocaine (with epinephrine) cornual nerve block and injectable meloxicam appears to effectively controls this pain, whereas our novel caustic paste containing $2.5 \%$ lidocaine and $2.5 \%$ prilocaine did not.

\section{Efficacy of a Cornual Nerve Block and Meloxicam}

The use of a cornual nerve block in our study appeared to be effective for the control of acute pain caused by caustic paste disbudding. Compared with the positive control group (P), calves in group B had lower respiratory rates and higher algometry scores, lower heart rates, and less pain behaviors for 1.5 to $3 \mathrm{~h}$ after paste application. Considerably fewer pain behaviors were observed for B as opposed to P or T calves. Skin

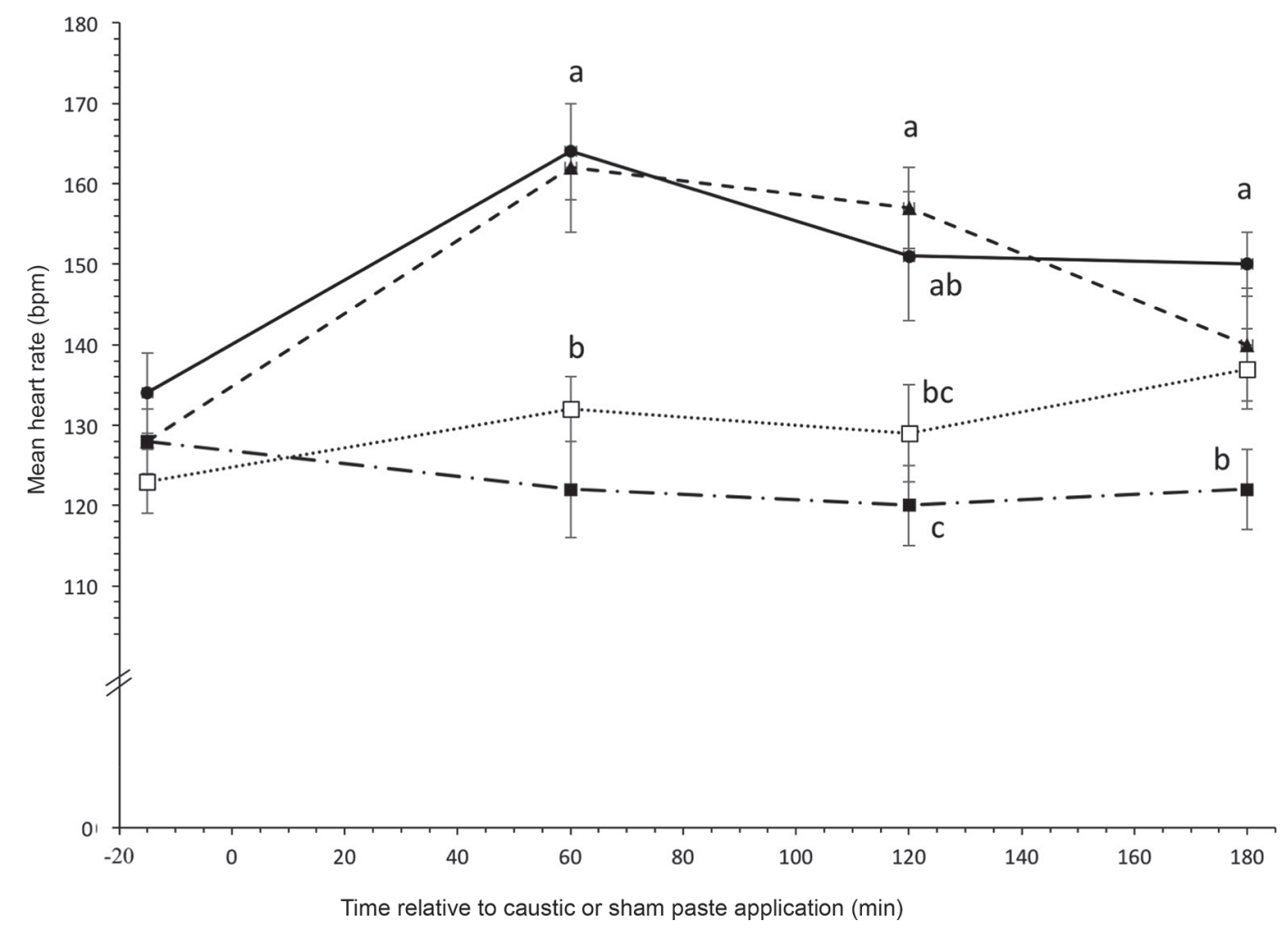

Figure 3. Mean heart rate [beats per minute (bpm); $\pm \mathrm{SE}$ ] by treatment group with SE bars plotted by time in minutes relative to disbudding with caustic or sham paste. Positive control group (commercial caustic paste and saline cornual nerve block; solid line with closed circular markers); topical anesthetic delivered in a novel caustic paste (novel caustic paste containing $2.5 \%$ lidocaine and $2.5 \%$ prilocaine, and saline cornual block; line with closed triangular markers); cornual nerve block [commercial caustic paste and $5 \mathrm{~mL}$ per side lidocaine (with epinephrine) cornual nerve block; dotted line with open square markers]; and sham group (placebo paste and saline cornual nerve block; dashed and dotted line with closed square markers). All groups received the saline or lidocaine cornual nerve block as well as injectable meloxicam (0.5 mg/kg of subcutaneously) at $15 \mathrm{~min}$ before disbudding. Different letters $(\mathrm{a}-\mathrm{c})$ reflect differences between treatment groups $(P<0.05)$ for a single time point. 
desensitization after cornual nerve block application has been shown to range from 107 to 512 min (mean of $304 \mathrm{~min}$; Fierheller et al., 2012); therefore, at 180 min, some calves in our study were beginning to regain sensation. In work examining the effect of a local block with and without flunixin meglumine, Stilwell et al. (2009) found differences in pain behaviors between calves that received lidocaine or lidocaine and flunixin meglumine as early as 40 min after disbudding. Fewer differences in pain behaviors were seen between the cornual blocked calves and the sham control groups in our study compared with that of Stilwell et al. (2009), and this may perhaps be a result of the use of lidocaine with epinephrine, possibly extending block duration. Although we did not see an effect of age on pain behaviors, mean age of calves in our study was younger than that of Stilwell et al. (2009).

Our findings are in contrast to Vickers et al. (2005), which may have been confounded by their application of local anesthetic as a ring block, and this is supported by the findings in their sham disbudding groups. In our study, neither S nor B groups showed a substantial number of pain behaviors throughout the observed time period. Further work on local anesthetic given to control the pain of caustic paste disbudding should focus on a cornual block; we question any benefit of a ring block over a cornual nerve block, as it requires 8 to 10 total injections (Fierheller et al., 2012), which, based on shallow needle depth is likely more difficult to apply to a nonsedated calf than a cornual nerve block. The efficacy of an acidic local anesthetic agent in the tissue surrounding the horn bud may be disrupted by the application of the alkaline paste; additionally, the needle insertions into the tissue could also impact the effect of the paste. Compared with a cornual nerve block, a ring block also has a significantly lower mean duration of anesthesia (147 min compared with $304 \mathrm{~min}$; Fierheller et al., 2012). Although a cornual nerve block requires some technical training, recent work by our research group has shown this can be taught to produc-

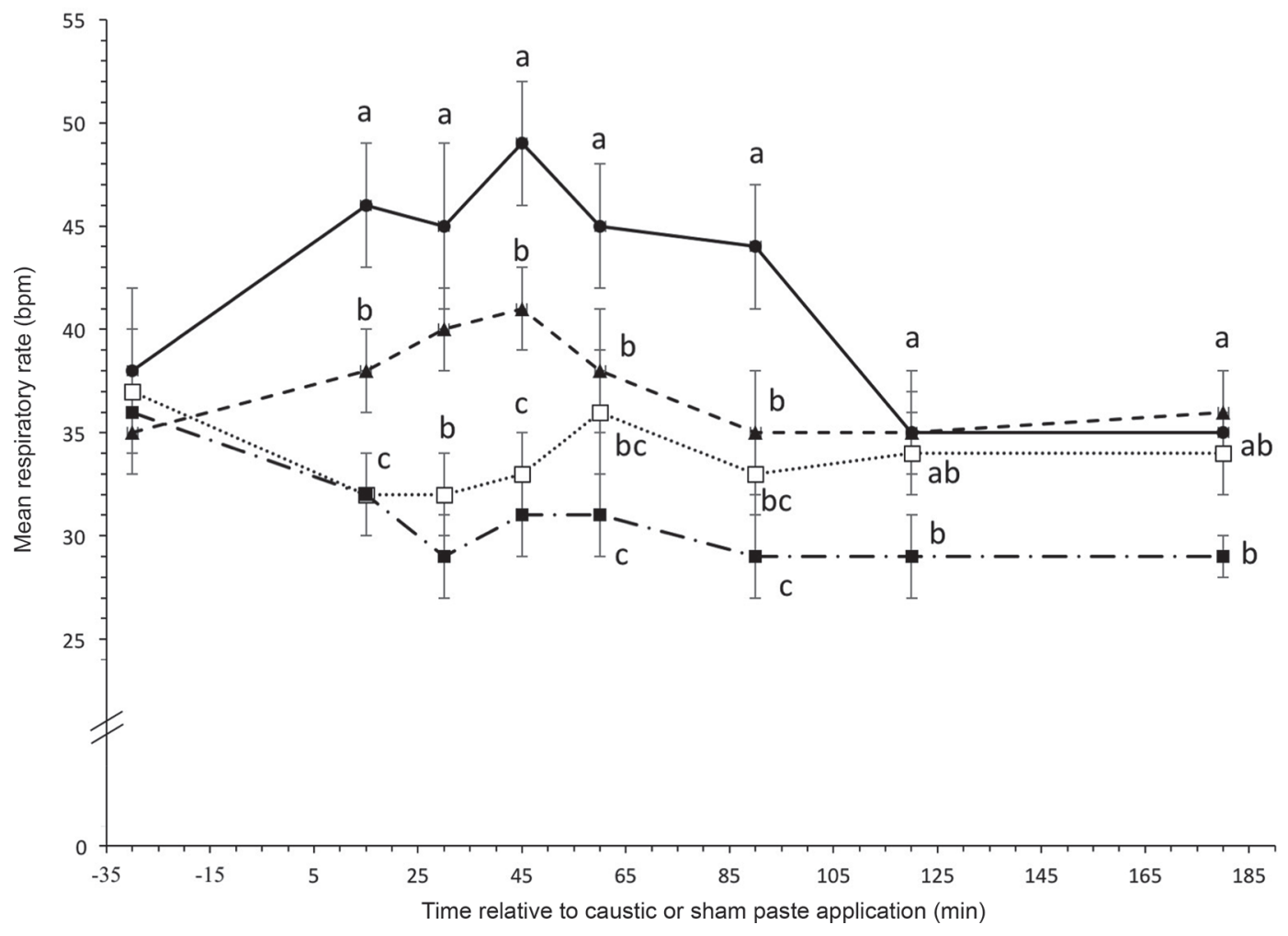

Figure 4. Mean respiratory rate [breaths per minute (bpm); $\pm \mathrm{SE}$ ] by treatment group with SE bars plotted by time in minutes relative to disbudding with caustic or sham paste. Positive control group (commercial caustic paste and saline cornual nerve block; solid line with closed circular markers); topical anesthetic delivered in a novel caustic paste (novel caustic paste containing $2.5 \%$ lidocaine and $2.5 \%$ prilocaine, and saline cornual block; dashed line with closed triangular markers); cornual nerve block [commercial caustic paste and $5 \mathrm{~mL}$ per side lidocaine (with epinephrine) cornual nerve block; dotted line with open square markers]; and sham group (placebo paste and saline cornual nerve block; dashed and dotted line with closed square markers). All groups received the saline or lidocaine cornual nerve block as well as injectable meloxicam $(0.5 \mathrm{mg} / \mathrm{kg}$ of subcutaneously) at $15 \mathrm{~min}$ before disbudding. Different letters $(\mathrm{a}-\mathrm{c})$ reflect differences between treatment groups $(P<0.05)$ for a single time point. 
ers effectively through a short hands-on training session (Winder et al., in press).

\section{Efficacy of the Novel Caustic Paste and Meloxicam}

The novel caustic paste containing $2.5 \%$ lidocaine and $2.5 \%$ prilocaine did not appear to be effective at controlling the pain of caustic paste disbudding in our study; pain behaviors, algometry measures, and heart rate did not differ between these calves and the positive control group (P) during any time points. The anesthetic in the novel paste is similar to the composition of the eutectic mixture of local anesthetics cream (Astra-Zeneca Canada Inc., Ontario, Canada) for desensitization of the skin in humans. Whereas the use of eutectic mixture of local anesthetics cream was found to be ineffective for desensitizing the horn buds of calves (Fierheller et al., 2012), even when applied up to 90 min before testing, our hypothesis was that the anesthetic agents in the caustic paste might work at deeper tissue levels as the paste penetrated the skin. Conceivably, another combination of anesthetic agents may be able to desensitize the tissue as the paste penetrates, although the extremely alkaline nature of the caustic paste poses a challenge for the stable inclusion of acidic anesthetic agents.

\section{Efficacy of Meloxicam Given Alone}

Although it has been shown that chemical disbudding is acutely painful when no pain control is given (Morisse et al., 1995; Stilwell et al., 2008), it is uncommon for North America dairy producers to use an anesthetic or analgesic when disbudding calves with this method (Adams et al., 2015; Winder et al., 2016). The work by Vickers et al. (2005) is often used as a reason that local anesthesia is not required for this method. In addition, the delayed pain response and promotion of this method as less painful than cautery may partly explain why producers are reluctant to adopt pain-control practices for caustic paste disbudding. The differences seen between our sham control group (S) and the positive control $(\mathrm{P})$ indicates that caustic paste disbudding is indeed acutely painful, even though both groups received injectable meloxicam. The lack of efficacy of an analgesic alone to control acute pain is consistent with that of Stilwell et al. (2008), using flunixin meglumine, and Braz et al. (2012), using an injectable opiate. The sham group's mean number of pain behaviors was very low and not different from baseline at all time points. This is different from Vickers et al. (2005), who found their local anesthetic protocol, which included a ring block, following sham disbudding, was associated with more pain behaviors than in calves without local anesthetic even though all calves were heavily sedated.

\section{Play and Feeding Behavior}

Whereas our primary outcomes were algometry scores and pain behaviors, we also explored a range of secondary outcomes, including play as an indicator of positive well-being. As less is known about the experience of pain in calves disbudded with caustic paste, it is important in caustic paste trials to examine multiple indicators of welfare. We saw more play behavior in sham calves than all disbudded groups. This differs from Mintline et al. (2013), where differences between local anesthetic alone and local anesthetic with NSAID were seen in calves disbudded with a hot iron. Mintline et al. (2013) used a separate pen from the calves' home pen, bedded deeply with fresh straw, where calves were tested with a companion. This is likely to have encouraged play as compared with our study, where calves were re-entered into their home pen without new bedding. That sham calves played more indicates a more positive affective state, which is similar to the conclusion from Neave et al. (2013), where even with some pain control (calves were disbudded with a hot-iron, given a lidocaine cornual nerve block and xylazine, but not an NSAID) calves subject to disbudding experienced negative judgment bias. Differences in total milk consumption, drinking speed, or meal size were not found between groups, despite the high feeding rate. However, a difference was seen in latency to drink from the automated feeder upon entry to the pen, where sham-disbudded calves tended to drink sooner than positive controls or topically treated calves ( $\mathrm{P}$ or $\mathrm{T}$ ), whereas cornual-blocked calves' latency was intermediate. Sham calves were generally more active upon entry to the group pen, both drinking sooner and playing more. Standing and lying behavior was not seen to be different among groups. Although our sample size may not have been large enough to capture differences in these secondary outcomes, it is also possible the effect of the NSAID (given to all groups) had begun to mitigate differences among the 3 disbudded groups at these later time points.

\section{Considerations}

The mean age of calves in our study (2.6 wk) is comparable to the age reported by caustic paste users in the 2014 NAHMS survey (2.3 wk; Adams et al., 2015); however, caustic paste is generally recommended at a younger age. Although age was not seen to have a significant effect on any outcomes aside from play be- 
havior, the trial was not designed to explore the effect of calf age. More research is needed to evaluate pain behavior and expression in very young calves.

Movement of the calves to individual pens was necessary to more easily assess measures that required restraint. Whereas we ensured calves spent $1 \mathrm{~h}$ in the pens before application of paste and the pens were located within their home pen, it is possible their expression of pain may have been different had they continued to stay with their group. The direction of this potential effect is unknown, but is expected to be similar for all calves. Calves in the cornual blocked group showed less sensitivity to pressure at the horn site for $3 \mathrm{~h}$ after compared with their sham counterparts; algometry may therefore be used as a less invasive measure of cornual block efficacy than the needle-prick test, which could be less acceptable in a caustic paste trial as needle holes may change the experience of pain on paste application in unsuccessful or unblocked groups.

\section{CONCLUSIONS}

Caustic paste disbudding appears acutely painful for at least $3 \mathrm{~h}$ after application, as assessed by changes in heart and respiratory rate, pressure sensitivity to the horn bud, and established pain-associated behaviors consisting of head shake, head rub, and tail flick. The use of a cornual nerve block effectively mitigated this pain for the duration of our study, whereas the novel caustic paste containing local anesthetics did not. We recommend calves disbudded with caustic paste be given a cornual nerve block to mitigate acute pain, in addition to an NSAID. Future work should be done to test the repeatability of the efficacy of a cornual nerve block, and should incorporate multiple measures of welfare to ensure that the experience of pain in calves disbudded with caustic paste is assessed adequately. Larger trials examining a possible confounding effect of calf age on disbudding should also be done, as current recommendations for disbudding before specific ages remain to be validated.

\section{ACKNOWLEDGMENTS}

The authors thank Laura Wright and the staff at the University of Guelph Dairy Research and Innovation Center for their contributions to this work. This project was funded by a Knowledge Translation and Transfer grant from the Agri-Food and Rural Link program of the Ontario Ministry of Agriculture, Food, and Rural Affairs - University of Guelph partnership (Guelph, Ontario, Canada).

\section{REFERENCES}

Adams, A. E., J. E. Lombard, C. S. Shivley, N. J. Urie, I. N. Roman-Muniz, C. P. Fossler, and C. A. Kopral. 2015. Management practices that may impact dairy heifer welfare on U.S. dairy operations. Page 105 in Proc. Joint Annu. Meet. Am. Dairy Sci. Assoc. Am. Soc. Anim. Sci., Orlando, FL. Am. Dairy Sci. Assoc., Champaign, IL.

American Veterinary Medical Association. 2014. Literature review on the welfare implications of the dehorning and disbudding of cattle. Accessed Dec 18, 2016. https://www.avma.org/KB/Resources/ LiteratureReviews/Pages/Welfare-Implications-of-Dehorning-andDisbudding-Cattle.aspx.

Bonk, S., O. Burfeind, V. S. Suthar, and W. Heuwieser. 2013. Technical note: Evaluation of data loggers for measuring lying behavior in dairy calves. J. Dairy Sci. 96:3265-3271.

Braz, M., M. Carreira, N. Carolino, T. Rodrigues, and G. Stilwell. 2012. Effect of rectal or intravenous tramadol on the incidence of pain-related behavior after disbudding calves with caustic paste. Appl. Anim. Behav. Sci. 136:20-25.

Bromberg, B. E., I. C. Song, and R. H. Walden. 1965. Hydrotherapy of chemical burns. Plast. Reconstr. Surg. 35:85-95.

Canadian Council on Animal Care. 1993. Guide to the Care and Use of Experimental Animals. Vol. 1, 2nd ed. Accessed May 8, 2017. http://www.ccac.ca/en_/standards/guidelines.

Canadian Veterinary Medical Association. 2010. Disbudding and dehorning of cattle-Position statement. Accessed Dec. 18, 2016. http://www.canadianveterinarians.net/documents/disbuddingand-dehorning-of-cattle.

Cozzi, G., F. Gottardo, M. Brscic, B. Contiero, N. Irrgang, U. Knierim, O. Pentelescu, J. J. Windig, L. Mirabito, F. Kling Eveillard, A. C. Dockes, I. Veissier, A. Velarde, C. Fuentes, A. Dalmau, and C. Winckler. 2015. Dehorning of cattle in the EU Member States: A quantitative survey of the current practices. Livest. Sci. 179:4-11.

Dairy Farmers of Canada. 2015. proAction: Leading the way for sustainable dairy farming; Providing assurance to customers about farm practices. Dairy Farmers of Canada, Ottawa, Ontario, Canada. Accessed Dec. 18, 2016. https://www.dairyfarmers.ca/Media/ Files/proaction/proaction_ang_lr15.pdf.

European Commission. 1988. The European Convention of 1976 for the Protection of Animals kept for Farming Purposes: Recommendation Concerning Cattle (Article 17). Accessed Mar.16, 2017. http://www.coe.int/t/e/legal_affairs/legal_cooperation/biological_safety_and_use_of_animals/farming/Rec\% 20cattle\%20E.asp.

Faulkner, P. M., and D. M. Weary. 2000. Reducing pain after dehorning in dairy calves. J. Dairy Sci. 83:2037-2041.

Fierheller, E. E., N. A. Caulkett, D. B. Haley, D. Florence, and L. Doepel. 2012. Onset, duration and efficacy of four methods of local anesthesia of the horn bud in calves. Vet. Anaesth. Analg. 39:431-435.

Heinrich, A., T. F. Duffield, K. D. Lissemore, and S. T. Millman. 2010. The effect of meloxicam on behavior and pain sensitivity of dairy calves following cautery dehorning with a local anesthetic. J. Dairy Sci. 93:2450-2457.

H.W. Naylor Co. Inc. 2015. Caustic paste disbudding. Accessed Dec. 18, 2016. http://www.dehorning.com/dehorning-methods/causticpaste-disbudding.

Milligan, B. N., T. F. Duffield, and K. D. Lissemore. 2004. The utility of ketoprofen for alleviating pain following dehorning in young calves. Can. Vet. J. 45:140-143.

Mintline, E. M., M. Stewart, N. R. Cox, G. A. Verkerk, J. M. Stookey, J. R. Webster, and C. R. Tucker. 2013. Play behavior as an indicator of animal welfare: Disbudding in dairy calves. Appl. Anim. Behav. Sci. 144:22-30.

Morisse, J. P., J. P. Cotte, and D. Huonnic. 1995. Effect of dehorning on behavior and plasma cortisol responses in young calves. Appl. Anim. Behav. Sci. 43:239-247.

National Farm Animal Care Council. 2009. Code of Practice for the Care and Handling of Dairy Cattle. Ottawa, Ontario, Canada. 
Accessed Dec. 18, 2016. http://www.nfacc.ca/pdfs/codes/dairy_ code_of_practice.pdf.

Neave, H. W., R. R. Daros, J. H. Costa, M. A. von Keyserlingk, and D. M. Weary. 2013. Pain and pessimism: Dairy calves exhibit negative judgment bias following hot-iron disbudding. PLoS One 8:e80556. https://doi.org/10.1371/journal.pone.0080556.

New Zealand National Animal Welfare Advisory Committee. 2005. Animal welfare (painful husbandry practices) code of welfare. Accessed Mar. 18, 2017. http://www.mpi.govt.nz/documentvault/1443.

Petrie, N. J., D. J. Mellor, K. J. Stafford, R. A. Bruce, and R. N. Ward. 1996. Cortisol responses of calves to two methods of disbudding used with or without local anaesthetic. N. Z. Vet. J. 44:9-14.

Stafford, K. J., and D. J. Mellor. 2005. Dehorning and disbudding distress and its alleviation in calves. Vet. J. 169:337-349.

Stafford, K. J., and D. J. Mellor. 2011. Addressing the pain associated with disbudding and dehorning in cattle. Appl. Anim. Behav. Sci. $135: 226-231$.

Stilwell, G., R. C. de Carvalho, M. S. Lima, and D. M. Broom. 2009. Effect of caustic paste disbudding, using local anaesthesia with and without analgesia, on behavior and cortisol of calves. Appl. Anim. Behav. Sci. 116:35-44.

Stilwell, G., M. S. Lima, and D. M. Broom. 2007. Comparing the effects of three different disbudding methods on behavior and plasma cortisol of calves. Rev. Port. Cienc. Vet. 102:281-288.

Stilwell, G., M. S. Lima, and D. M. Broom. 2008. Comparing plasma cortisol and behavior of calves dehorned with caustic paste after non-steroidal anti-inflammatory analgesia. Livest. Sci. 119:63-69.
Stock, M. L., S. L. Baldridge, D. Griffin, and J. F. Coetzee. 2013. Bovine dehorning: Assessing pain and providing analgesic management. Vet Clin. North Am. Food Anim. Pract. 29:103-133.

Vasseur, E., F. Borderas, R. I. Cue, D. Lefebvre, D. Pellerin, J. Rushen, K. M. Wade, and A. M. de Passille. 2010. A survey of dairy calf management practices in Canada that affect animal welfare. J. Dairy Sci. 93:1307-1315.

Vickers, K. J., L. Neil, L. M. Kiehlbauch, and D. M. Weary. 2005. Calf response to caustic paste and hot-iron dehorning using sedation with and without local anesthetic. J. Dairy Sci. 88:1454-1459.

Villarroel, A. 2010. Dehorn calves early. Hoard's West. Accessed Dec. 18, 2016. http://cdn2.hubspot.net/hub/23116/file-13456916-pdf/ docs/dehorn-calves-early-hoards-nov-2010.pdf?t=1371586812000.

Von Keyserlingk, M. A., and D. M. Weary. 2015. Current issues in animal welfare-What must be done and how to improve. Proc. 2015 Western Dairy Management Conference, Reno, N.V. Accessed Dec. 18, 2016. http://wdmc.org/2015/von\%20Keyserlingk.pdf .

Winder, C. B., S. J. LeBlanc, D. B. Haley, K. D. Lissemore, M. A. Godkin, and T. F. Duffield. 2016. Practices for the disbudding and dehorning of dairy calves by veterinarians and dairy producers in Ontario, Canada. J. Dairy Sci. 99:10161-10173.

Winder, C. B., S. J. LeBlanc, D. B. Haley, K. D. Lissemore, M. A. Godkin, and T. F. Duffield. Comparison of an online learning module to hands-on training in teaching cautery disbudding technique for dairy calves, including cornual nerve block application. Can. Vet. J. In press. 